\title{
Fallopian Tube Papilloma - Case Report of a Rare Tumor
}

\author{
Narasimhaiah A, Ansari M, Haritwal A, Awasthi S
}

Department of Pathology

TMMC and RC

Moradabad,UP

India

\section{ABSTRACT}

Fallopian tube neoplasms are rare. We report a rare case of fallopian tube papilloma

Corresponding Author discovered incidentally in a 45 year old female, operated for procidentia. Right tube was dilated at the infundibular region, with friable grey white tissue in the lumen.

Arathi Narasimhaiah

Department of Pathology

TMMC and RC

Moradabad,UP

India Microscopy showed delicate branching papillae lined by a single layer of epithelium resembling tubal lining. There were no features to suggest a reactive hyperplasia in response to inflammation or of aggressive behaviour.

\section{KEY WORDS}

Epithelial lesions, fallopian tube papilloma, metaplastic papillary tumor, proliferative

E-mail: arathin10@gmail.com

Citation

Narasimhaiah A, Ansari M, Haritwal A, Awasthi S.

Fallopian Tube Papilloma - Case Report of a Rare

Tumor. Kathmandu Univ Med J 2013;43(3):250-152.

\section{INTRODUCTION}

Neoplasms of the fallopian tube are rarely encountered, be it benign or malignant. Papillomas are benign tumors which might be discovered incidentally or present as an adnexal mass. ${ }^{1}$ They need to be differentiated from a gamut of lesions, both reactive and neoplastic, like metaplastic papillary tumor, reactive hyperplasia associated with salpingitis and serous papillary carcinoma.

\section{CASE-REPORT}

A 45 year old Para5 Live3 Abortion2 female presented with procidentia to the gynaecology OPD of a tertiary hospital. Her last delivery was 19 yrs back and she had attained menopause two years back. Hysterectomy with right salpingo-oophorectomy specimen was received. On gross examination, cervix was hypertrophied and myometrium showed trabeculations. The fallopian tube measured 6.5 $\mathrm{cm}$, distal $3.0 \mathrm{~cm}$ towards fimbria showed dilatation, with a circumference of $1.5 \mathrm{~cm}$. Cut surface showed a grey white, friable tissue within the dilated lumen (Fig 1).Microscopy of the tubal lesion showed delicate branching papillae filling the lumen, these arising from tubal lining epithelium, lined by a single layer of tall columnar epithelium, some of the cells showing cilia (Fig 2).There was no significant atypia or mitotic activity. Inflammation was not identified. A diagnosis of benign papilloma of the fallopian tube was rendered. 


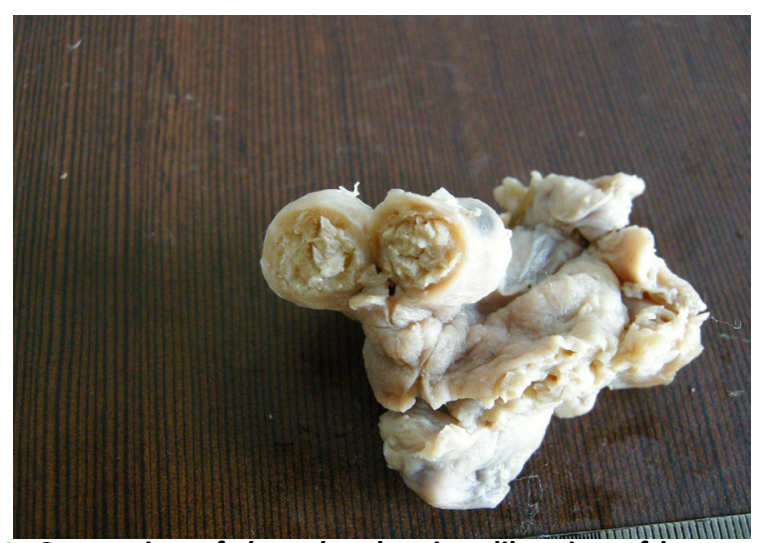

Figure 1. Cut section of the tube showing dilatation of lumen, filled with grey-white friable tissue.

\section{DISCUSSION}

Proliferative epithelial lesions of the fallopian tube include both neoplastic and non-neoplastic categories. The list of benign neoplasms includes polypoid adenofibromas, papilloma and benign serous adenoma. ${ }^{2}$ These lesions are rarely encountered even though fallopian tubes are common surgical pathology specimens either as part of hysterectomy or as only tubal resections. In fact, our search of the English literature yielded very few case reports. ${ }^{1,3,4}$ Reporting a case of fallopian tube papilloma, the author Gisser SD emphasises the rarity of recorded case of papillomas, and mentions that the other true papilloma case could be the one found incidentally in a review of tubal pathology over a 40 year period. ${ }^{1}$ However an earlier report by Ries $\mathrm{E}$ mentions that six cases have been documented in the literature and their case of tubal papilloma in a 34 year old patient being the $7^{\text {th }}$ reported case. ${ }^{3}$ Kaspersen et al describe a case of tubal papilloma in a woman with primary sterility. ${ }^{4}$ Fallopian tube papilloma can be discovered incidentally, as in our case or can be symptomatic, presenting as a mass lesion. In the case reported by Gisser SD, a unilateral rapidly enlarging adnexal mass was noticed in a 41 year old woman. ${ }^{1}$

Papillomas are more common in the infundibular portion of the tube. ${ }^{2}$ Grossly, the case described by Gisser SD showed dilated infundibular portion of the tube with a soft exophytic pale yellow lesion within. ${ }^{1}$ In our case the lesion was brought to attention by the dilated tube adjacent to the fimbria, with lumen showing friable greywhite tumor.Microscopy showed a delicate branching papillae arising from the tubal epithelium. The cells were single layered, columnar. Since the morphology was bland without significant atypia/mitotic activity, a diagnosis of tubal papilloma was made. The microscopic appearance of the case described by Gisser SD differs from our case in being two layered to multilayered. The author also noted that the papilloma appeared to have arisen from an adjacent contiguous area of fimbrial hyperplasia. ${ }^{1}$ Zheng et al describe a case of borderline papillary serous tumor of the fallopian tube in a 31 year old woman who presented with lower abdominal pain and subsequently a mass was

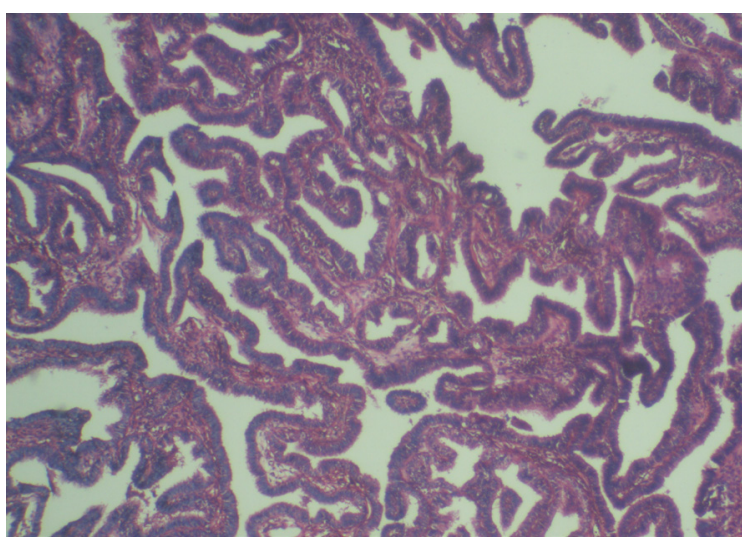

Figure 2. Photomicrograph showing delicate branching papillae (X40 $\mathrm{H}$ and $\mathrm{E}$ ).

discovered on sonogram. The left tube showed dilatation toward fimbrial end, containing yellow-tan polypoid mass with cauliflower like surface. The histology of the tumor resembled that of an ovarian borderline serous tumor. A diagnosis of borderline papillary serous tumor was rendered, based on papillae, stratification, nuclear atypia and mitoses. This diagnostic category had not been previously used in fallopian tube. The authors mention that to the best of their knowledge, 6 such cases have been described in the English literature. ${ }^{5}$

The other differential of concern will be a fallopian tube cancer which is a rare gynaecologic malignancy. In their study spanning 33 years Eddy et al found an incidence of $0.36 \%{ }^{6}$ In the retrospective study by Rose et al during a period of 23 years, 40 cases were detected to be primary fallopian tube cancer and in another 24 cases, tube was involved as a part of multifocal upper genital malignancy. There was transition from in situ to invasive carcinoma in thirteen cases. ${ }^{7}$

It is important to identify a proliferative lesion correctly as in-situ carcinoma. Moore et al opine that a papillary or solid lesion which is mitotically active could represent pre invasive carcinoma. ${ }^{8}$ We did not find any mitotic activity in our case. Gisser SD mentions that in her case mitotic activity was almost absent. ${ }^{1}$

There are several non-neoplastic papillary lesions in the fallopian tube which can mimic the neoplastic category. Exuberant tuabal papillary proliferations are quite common in a case of salpingitis and a diagnosis of papilloma should not be rendered when there is significant inflammation or distortion of plicae. ${ }^{9}$ In our case, the papillae were delicate and there was neither inflammation nor distortion of plicae. Sometimes the hyperplasia associated with inflammation is so exuberant as to mimic carcinoma of the fallopian tube. In 14 such cases of Cheung et al, the young age of the patients, not finding tumor grossly and severe chronic inflammation, along with mild atypia, helped in arriving at a correct diagnosis. ${ }^{10}$ TB salpingitis has also been known to be associated with pseudocarcinomatous changes. ${ }^{11}$ Another entity that needs to be considered in non neoplastic category is metaplastic papillary tumor. 
Typically encountered in post-partum state, this entity is characterised by cells having eosinophilic cytoplasm. ${ }^{2}$ Ultrastructural study done by Keeney and Thrasher showed abundant parallel wavy filaments. ${ }^{12}$ Categorisation of this lesion as metaplastic or neoplastic is controversial though it is generally considered to be non- neoplastic. ${ }^{11,13}$

Moore and Enterline, in order to find out significance of proliferative epithelial lesions of the fallopian tube studied the entire tube (unilateral/bilateral) in 124 cases. Consecutive cases of hysterectomy were chosen, irrespective of the indication. On microscopy, 23 cases showed changes which they categorized as proliferative epithelial lesion, commonly involving a part of the section. There was associated salpingitis in $48 \%$ of the cases. They conclude that proliferative epithelial lesion can be detected if carefully looked for and these lesions are highly unlikely

\section{REFERENCES}

1. Gisser SD. Obstructing Fallopian Tube Papilloma. Int J Gynecol Pathol. 1986;5:179-82.

2. I.Alvarado-Cabrero, A.Cheung, R.Caduff. Tumors of the fallopian tube and uterine ligaments. In: Tavassoli FA and Devilee P, eds. Pathology and Genetics Tumors of the Breast and Female Genital Organs. Lyon: IARC Press. 2003:204-215.

3. Ries E. Primary Papilloma and Primary Carcinoma of the Fallopian Tube. JAMA. 1987;XXVIII(21):962-968.

4. Kaspersen P, Buhl L and Meller R. Fallopian Tube Papilloma in a Patient with Primary Sterility. Acta Obstetricia et Gynecologica Scandinavica 1988;67:93-94.

5. ZhengW, KramerEE, CoxKA, Hoda SA. Borderline Papillary Serous Tumor of the Fallopian Tube. Am J Surg Pathol. 1996;20:30-35.

6. Eddy GL, Copeland LJ, Gershenson DM, Atkinson EN, Wharton JT and Rutledge FN. Fallopian Tube Carcinoma. Obstet Gynecol. 1984;64:546552.

7. Rose PG, Piver MS and Tsukada Y. Fallopian Tube Cancer The Roswell Park Experience. Cancer. 1990;66:2661-2667. to represent non-invasive carcinoma. No additional treatment is required when detected incidentally. ${ }^{8}$

It should be noted that in the above study the lesions were detected microscopically and there is no mention of any grossly appreciable papillary lesions, though 9 cases showed papillae on histology. As far as the behaviour of papillomas is concerned, their malignant potential is unknown. ${ }^{9}$ Zheng et al opine that conservative treatment may be adequate for the tumor described by them as 'borderline papillary serous tumor. ${ }^{5}$

In conclusion, it is important to correctly recognise the rare entity of fallopian tube papilloma and distinguish it from various non-neoplastic epithelial proliferative lesions on one hand and the in-situ carcinoma on the other, with its more serious implications. Management of the papilloma can be conservative even when symptomatic.

8. Moore SW and Enterline HT. Significance of Proliferative Epithelial Lesions of the Uterine Tube. Obstetrics and Gynecology. 1975;45:385390.

9. Wheeler JE. Diseases of the Fallopian tube. In: Kurman RJ ed, Blaustein's Pathology of the Female Genital Tract. 5thed. India:Springer-Verlag; 2002 617-648.

10. Cheung ANY, YoungRH, Scully RE. Pseudocarcinomatous Hyperplasia of the Fallopian Tube Associated with Salpingitis: A Report of 14 Cases. Am J Surg Pathol. 1994;18:1125- 30.

11. Young RH, Clement PB, Scully RE. The Fallopian Tube and Broad Ligament. In: Mills SE,ed.Sternberg's Diagnostic Surgical Pathology. 4th ed. India: Jaypee Brothers Medical Publisher Ltd; 2004. pg. 26532675.

12. Keeney GL and Thrasher TV. Metaplastic Papillary Tumor of the Fallopian Tube:A Case Report with Ultrastructure. Int J Gynecol Pathol. 1988;7:86-92.

13. Fallopian Tube (including broad and round ligament). In:Juan Rosai ed. Rosai Ackerman's Surgical Pathology. 9th ed. India: Elsevier; 2004 pg.1636-1648. 